\title{
SWAT hydrologic model parameter uncertainty and its implications for hydroclimatic projections in snowmelt-dependent watersheds
}

Darren L. Ficklin ${ }^{1 *}$ and Bradley L. Barnhart ${ }^{2}$

${ }^{1}$ Department of Geography, Indiana University, 701. E. Kirkwood Ave., Bloomington, IN 47405

${ }^{2}$ Independent contractor, Corvallis, OR 97330

*corresponding author. Address: ${ }^{1}$ Department of Geography, Indiana University, 701. E. Kirkwood Ave., Bloomington, IN 47405. Phone: 812-856-5047. Email: dficklin@indiana.edu 


\section{Abstract}

The effects of climate change on water resources have been studied extensively throughout the world through the use of hydrologic models coupled with General Circulation Model (GCM) output or climate sensitivity scenarios. This paper examines the effects of hydrologic model parameterization uncertainty or equifinality, where multiple unique hydrologic model parameter sets can result in adequate calibration metrics, on hydrologic projections from downscaled GCMs for three snowmeltdependent watersheds (upper reaches of the Clearwater, Gunnison, and Sacramento River watersheds) in the western United States. The hydrologic model used in this study is the Soil and Water Assessment Tool (SWAT) and is calibrated for discharge at the watershed outlet in each watershed. Despite achieving similar calibration metrics, a majority of hydrologic projections of average annual streamflow during the 2080s were statistically different, with differences in magnitude and direction (increase or decrease) compared to historical annual streamflows. At the average monthly time-scale, a majority of the hydrologic projections varied in peak streamflow timing, peak streamflow magnitude, summer streamflows, as well as overall increases or decreases compared to the historical monthly streamflows. Snowmelt projections from the SWAT model also widely varied, both in depth and snowmelt peak timing, for all watersheds. Since a large portion of the runoff-producing regions in the western United States is snowmelt-dependent, this has large implications for the prediction of the amount and timing of streamflow in the coming century. This paper shows that hydrologic model parameterizations that give similar adequate calibration metrics can lead to statistically significant differences in hydrologic projections under climate change. Therefore, researchers and water resource 
managers should account for this uncertainty by assembling ensemble projections from both multiple parameter sets and GCMs.

Keywords: climate change; hydrologic modeling; equifinality; SWAT; western United States; watershed

\section{Introduction}

The potential impact of climate change on water resources has been studied extensively throughout the world through the use of calibrated hydrologic models coupled with General Circulation Model (GCM) output (either raw or downscaled) and/or precipitation and temperature climate sensitivity scenarios (e.g., Arnell and LloydHughes, 2014; Barnett et al., 2008). However, hydrologic projections using climate change scenarios are subject to uncertainties related to both hydrological model uncertainties and climate input data. It is important to acknowledge and investigate the extent of these uncertainties in order to better prepare future water resource management scenarios under a changing climate.

Climate change projection uncertainties arise from the choice of projected greenhouse gas emission pathway (Kim et al., 2013; Maurer, 2007), the structure and parameterization of the GCM (Ficklin et al., 2013; Harding et al., 2012), the GCM downscaling procedure (Chen et al., 2011a; Gutmann et al., 2012), and the initial GCM conditions (Chen et al., 2011b). To further quantify climate change uncertainty, researchers use multiple GCMs (termed GCM ensemble) to assess the spread of projections (Murphy et al., 2004). 
Additional studies have found that hydrologic model uncertainty can also be a significant source of climate change uncertainty. Minville et al. (2008) applied two different types of hydrologic models (lumped vs. distributed) to the Chute-du-Diable watershed in Canada, and concluded that differences in hydrologic models can produce a large uncertainty signal on summer streamflows. Jiang et al. (2007) applied six rainfallrunoff models with sixteen hypothetical climate change scenarios on the Dongjian Basin in southern China and found that the models projected different future hydrologic conditions even though the models performed similarly during the historical time period. By comparing a lumped conceptual model and a spatial-distributed physically-based model, Poulin et al. (2011) determined that the impact of hydrological model structure uncertainty is more significant than model parameter uncertainty. Lastly, Brigode et al. (2013) indicate that hydrologic models, and the calibration procedures used with these models, are a large source of climate change uncertainty and their robustness must be improved.

Wilby and Harris (2006) discuss these aforementioned uncertainties in detail and ranked their importance in decreasing order as follows: differences in GCM output, downscaling methods, hydrological model structure, hydrological model parameters, and then greenhouse gas emission scenario. A number of studies have agreed with Wilby and Harris (2006), indicating that the largest source of these uncertainties are from the differences in GCMs. Prudhomme and Davies $(2009 a, b)$ researched the effects of climate change uncertainties on four British catchments (Ithon, Medway, South Tyne, and Medway), considering two greenhouse gas emission scenarios, three GCMs, two downscaling techniques, two different versions (simple vs. complex) of the same 
conceptual model, and hydrologic parameter uncertainty. They concluded that the largest source of uncertainty stemmed from the choice of GCM with a caveat that hydrologic model/parameter uncertainty cannot be ignored. On two river basins in England (Beult River at Stile Bridge in southeast England and the Duddon River at Duddon Hall in northwest England), Kay et al. (2009) also concluded that the choice of GCM was a large portion of the uncertainty.

Recently, the effects of hydrologic model non-uniqueness, or equifinality (Beven, 2006), where multiple hydrological model parameter sets produce similar or acceptable model outputs, on climate change projections have become an important area of research. In fact, quantification of this model uncertainty has been investigated extensively in recent years for several different hydrologic models (Chen et al., 2011b; Poulin et al., 2011; Steffens et al., 2014). These studies suggest that multiple hydrologic models with multiple calibration sets should be considered when making management decisions.

This paper seeks to expand this present literature to examine the potential source of uncertainty in hydrologic model parameterization or equifinality, specifically for the Soil and Water Assessment Tool (SWAT; Arnold et al, 1998) for snowmelt-dependent watersheds in the western United States. We analyze three distinct, important water resource regions in the western United States, including the upper Clearwater River watershed (a tributary of the Snake River basin), the Gunnison River watershed (a tributary of the Colorado River watershed), and the upper Sacramento River watershed. We use SWAT to investigate the effects of parameter uncertainty on projected streamflow and snowmelt simulations in these watersheds. To the authors' knowledge, equifinality in the SWAT model has yet to be explored for climate change purposes. Five 
model parameter sets for each watershed that result in acceptable model output based on calibration and validation statistics are input with downscaled climate change projections from five GCMs. Based on the output from each model parameter set for each region, the variability of hydrologic projections is assessed. These results indicate important implications for using and interpreting SWAT results when coupled with GCM ensembles.

\section{Methods and material}

\subsection{Study Sites}

Three western United States snowmelt-dependent watersheds were chosen for this analysis: the Clearwater River watershed near Beaver Creek (hereafter Clearwater River watershed), Gunnison River watershed at Whitewater, Colorado (hereafter Gunnison River watershed), and Sacramento River watershed at Lake Shasta (hereafter Sacramento River watershed) (Figure 1). Each watershed is a tributary for the three major water resource regions in the western United States: the Columbia River watershed, Colorado River Watershed, and Sierra Nevada mountain range. The physical and climatic characteristics of each watershed can be found in Table 1. Additionally, the watershed outlets as defined for this study are found in Table 1. Overall, it can be seen that the three watersheds vary by climate, elevation, and streamflow rates. Additionally, these three watersheds come from different snowpack regimes (Trujillo and Molotch, 2014). Therefore these watersheds should give a unique representation about how model uncertainty may influence hydrologic projections for these three western U.S. regions and other snowmelt-dependent regions throughout the world. 


\subsection{Hydrologic Model}

SWAT is a basin-scale hydrologic model designed to simulate watershed and water-quality processes by modeling the entire hydrologic cycle. In SWAT, large watersheds are divided in sub-watersheds, which are then divided into Hydrologic Response Units (HRUs). For this study, surface runoff was estimated using the Soil Conservation Service Curve Number. Any water that does not become surface runoff enters the soil column where it can be removed by evapotranspiration (ET), deep percolation into the deep aquifer, or move laterally in the soil column for streamflow contribution. Groundwater contribution to streamflow can be generated from shallow and deep aquifers and is based on the groundwater balance. The Penman-Monteith method was used to estimate ET. Relative humidity and solar radiation inputs were generated based on nearby weather gauges using the built-in SWAT stochastic weather generator. The model was run at a monthly time step for the historic time period (1970-2005 for the Clearwater River watershed; 1960-2005 for the Gunnison River watershed; 1950-2005 for the Sacramento River watershed) and one future time period (2081-2099; defined as 2080s). A technical description of SWAT can be found in Neitsch et al. (2005).

The watersheds simulated in this study are snowmelt-dependent and thus discussion on how SWAT simulates snow accumulation and snowmelt is warranted. SWAT simulates snowmelt using the temperature-index method based on the work of Fontaine et al. (2002). When daily mean air temperature is less than a snowfall temperature, as specified by the SWAT variable SFTMP, the precipitation within an HRU is classified as snow, and the liquid water equivalent is added to the already-present snowpack. The total snowpack increases with additional snowfall, but decreases with 
snowmelt events.

The mass balance of the snowpack in each HRU is as follows:

$$
S N O_{i}=S N O_{i-1}+R_{S f, i}-E_{S u b, i}-S N O_{m l t, i}
$$

where $S \mathrm{NO}_{i}$ and $\mathrm{SNO}_{i-1}$ are the water equivalents of the snowpack on the current day of the year $(i)$ and previous $(i-1)$ day, $R_{s f, i}$ is the water equivalent of the snow precipitation on day $i, E_{s u b, i}$ is the water equivalent of the sublimation on day $i$, and $S N O_{m l t, i}$ is the water equivalent of the snowmelt on day $i$.

Since snowpack is rarely uniformly distributed over a region with topography, SWAT uses an areal depletion curve to describe the growth and recession of the snowpack (Anderson, 1976) and is defined as:

$$
s n o_{c o v, i}=\frac{S N O_{i}}{S N O C O V M X}-\left[\frac{S N O_{i}}{S N O C O V M X}+\exp \left(\operatorname{cov}_{1}-\operatorname{cov}_{2} * \frac{S N O_{i}}{S N O C O V M X}\right)\right]^{-1}
$$

where $s n o_{c o v, i}$ is the fraction of the HRU covered by snow on the current day $(i)$, SNOCOVMX is the minimum snow water content that corresponds to $100 \%$ snow cover (in $\mathrm{mm} \mathrm{H}_{2} \mathrm{O}$ ) and $\operatorname{cov}_{1}$ and $\operatorname{cov}_{2}$ are the coefficients that define the shape of the areal depletion curve, which are found by solving the above equation for two known points: (1) 95\% coverage at $95 \%$ SNOCOVMX and (2) 50\% coverage at a fraction of SNOCOVMX, specified by the SWAT parameter SNO5OCOV.

The temperature of the snowpack and the melting rate also controls snowmelt. Anderson (1976) found that snowpack temperature is strongly influenced by the mean daily temperature of the preceding day's snowpack temperature and varies as a dampened function of air temperature. The influence of the previous day's snowpack temperature on the current day's snowpack temperature is described by a lag factor, specified by the 
SWAT variable TIMP, which is a lumped parameter that accounts for snowpack density, water content, and exposure to the sun. The temperature of the snowpack is calculated by:

$$
T_{s p, i}=T_{s p, i-1}(1-T I M P)+\overline{T_{a, l}} * \operatorname{TIMP}
$$

where $T_{s p, i}$ and $T_{s p, i-1}$ are the snowpack temperatures on the current day $(i)$ and previous day $(i-1)$, respectively, and $\overline{T_{a, l}}$ is the mean air temperature on day $i$. As TIMP approaches $1, \overline{T_{a, l}}$ exerts a large influence on $T_{s p, i}$. Conversely, as TIMP nears $0, T_{s p, i-1}$ becomes more important.

Snowmelt can then be calculated as:

$$
S N O_{m l t, i}=b_{m l t, i} * S n o_{c o v, i} *\left[\left(\frac{T_{s p, i}+T_{\max , i}}{2}\right) *-S M T M P\right]
$$

where $T_{\max , i}$ is the maximum air temperature on day $i\left({ }^{\circ} \mathrm{C}\right), S M T M P$ is the base temperature above which snowmelt is produced $\left({ }^{\circ} \mathrm{C}\right)$, and $b_{m l t, i}$ is the melt factor on day $i$ (mm $\mathrm{H}_{2} \mathrm{O} /{ }^{\circ} \mathrm{C}$-day), which is calculated as:

$$
b_{m l t, i}=\frac{S M F M X+S M F M N}{2}+\frac{S M F M X-S M F M N}{2} * \sin \left[\frac{2 \pi}{365}(i-81)\right]
$$

where SMFMX and SMFMN are the maximum and minimum snowmelt factors, respectively ( $\mathrm{mm} \mathrm{H}_{2} \mathrm{O} /{ }^{\circ} \mathrm{C}$-day). Snowmelt then enters the stream via surface runoff or infiltrates into the soil column. Here we define snowmelt as a unit of depth (mm) per $\mathrm{km}^{2}$ of watershed area.

\subsection{Hydrologic model input data}

SWAT inputs of topography, land cover, and soils data were compiled from federal and state databases. Topography for slope and watershed delineation was extracted from Digital Elevation Models from the United States Geological Survey (Gesch et al., 2002). The National Land Cover Database version 2001 was used for the 
land cover (Homer et al., 2004). The State Soil Geographic Database (STATSGO) was used for physical soil properties (Wolock, 1997). Gridded meteorological data from Maurer et al. (2002) was used for the historical climate. Natural flow data (i.e., streamflow without human interference) that was used for streamflow calibration were obtained from the California Department of Water Resources for the Upper Sacramento River watershed, the United States Bureau of Reclamation for the Upper Gunnison River watershed, and the United States Geological Survey for the Clearwater River watershed. SWAT was run using monthly time steps.

Climatic projections from 5 GCMs (Table 2) and one representative concentration pathway (RCP 8.5) from the Coupled Model Intercomparison Project - Phase 5 (CMIP5) dataset were used to drive the calibrated SWAT model. Daily-downscaled output were obtained from the Downscaled CMIP3 and CMIP5 Climate and Hydrology Projections archive (USBR, 2011). RCP 8.5 represents the highest greenhouse gas emissions pathway and corresponding increase in radiative forcing. Downscaling was achieved by using the daily bias-corrected and constructed analogs (BCCA) method (Maurer et al., 2010).

\subsection{Model parameter sets}

To achieve calibration, SWAT model parameters were varied within a physically meaningful range for each watershed (Neitsch et al., 2005) within the automatic calibration program SWAT Calibration and Uncertainty Procedures (SWAT-CUP) (Abbaspour et al., 2007):

$$
b_{\mathrm{j}}: b_{\mathrm{j}, \text { abs_min }} \leq b_{\mathrm{j}} \leq b_{\mathrm{j}, \text { abs_max }}
$$

where $b_{\mathrm{j}}$ is the model parameter, $b_{\mathrm{j}, \text { abs_min }}$ and $b_{\mathrm{j}, \text { abs_max }}$ are the model parameter minimum and maximum range and $j$ is the index of the model parameter set, varying from 1 to $m$, to 
produce $m$ model parameter sets. Based on previous SWAT model experience of the western United States, model parameters were included that are related to surface hydrology, groundwater hydrology, snowpack accumulation, and snowmelt. See Supplementary Table 1 information for the SWAT parameter descriptions and their maximum and minimum ranges. Latin Hypercube sampling (McKay et al., 1979) using a uniform probability distribution for each hydrologic model parameter was then carried out, leading to $m$ different sets of parameter combinations, (with $m=700$ for this work for each parameter set). The SWAT models were then run for each of the $m$ parameter combinations to allow $m$ comparisons of observed and simulated streamflow at the outlet of each watershed.

\subsection{Model verification}

To assess model goodness-of-fit from the different model parameter sets, we use four commonly-used model efficiency statistics: the Nash-Sutcliffe coefficient [main objective function (NS; Nash and Sutcliffe (1970)], coefficient of determination $\mathrm{R}^{2}$, root mean square error (RMSE), and percent bias. The NS coefficient was used as the main objective function used in SWAT-CUP, while all statistics were used in the making the final decision of the top five best parameter sets. The top five parameter sets for each region were then input with downscaled climate scenarios. The selection of adequate calibrations decreased dramatically after the top five parameter sets.

\subsection{Statistical Analyses}

Parameter and GCM uncertainties were performed for the 2080s time period, defined as 2081-2099. The historical time period is defined as 1970-1989 for the Clearwater River watershed, 1960-1979 for the Gunnison River watershed, and 1950- 
1969 for the Sacramento River watershed. Uncertainty from the different SWAT model parameterizations was assessed by comparing 5 acceptable parameter sets, each set then forced with 5 downscaled climate scenarios. This gives a total of 25 model runs for each watershed. The parameter uncertainty was assessed by comparing the GCM ensemble average, maximum, and minimum streamflow of each particular parameter set with GCM runs at the annual and monthly time scales. For the annual time scale, the average annual streamflow for 2081-2099 for each parameter set was found by taking the average annual streamflow of the $5 \mathrm{GCM}$ ensemble. The ensemble average maximum and minimum streamflows were determined by finding the maximum and minimum streamflows of the average annual streamflow from the GCM ensemble for a particular parameter set. The same analysis was performed at the monthly time scale. Additionally, the same monthly analysis was performed for snowmelt depth for each watershed. Significant differences between streamflow outputs for all parameter sets for each watershed (10 in total) were assessed using the Kolmogorov-Smirov test at $\mathrm{p}=0.05$. Significant differences for annual and monthly streamflows were also determined against historical data.

\section{Results}

\subsection{Calibration results}

Figure 2 and Table 3 present the calibration and validation results for the three western United States watersheds as compared to observed, natural streamflow data. Figure 2 shows kernel density estimations of the errors between the observed and simulated streamflow for all watersheds and for both the calibration and validation periods, respectively. Overall, Figure 2 and Table 3 show that all SWAT simulations for all three watersheds adequately captured the streamflow variability and amount for the 
calibration and validation time periods, with an overall validation NS parameter set average (range) of $0.76(0.17), 0.72(0.15)$, and $0.86(0.06)$ for the Clearwater River watershed, Gunnison River watershed, and Sacramento River watershed, respectively. Note that previous studies have declared monthly flow simulations from SWAT as 'Satisfactory' for NS values greater than 0.5 , 'Good' for NS values greater than 0.65 , and 'Very good' for NS values greater than 0.75 (Moriasi et al., 2007; Santhi et al., 2001). Average calibration and validation percent bias for the parameter sets is 20 and $13 \%$ for the Clearwater River watershed, -11.6 and $-9 \%$ for the Gunnison River watershed, and 1.4 and $-7 \%$ for the Sacramento River watershed (Table 3). The bias can also be visualized in Figure 2 as offsets from the origin (vertical line in Figure 2). Moriasi et al. (2007) also declare monthly streamflow simulations to be satisfactory, good, and very good when the absolute percent bias is between 15 and 25\%, 10 and 15\%, and less than $10 \%$, respectively. See Table 3 for other model calibration and validation statistics. Overall, all results indicate at the minimum a satisfactory calibration based on the model calibration and validation requirements from Moriasi et al. (2007). Also note that a sign of unsatisfactory calibration or overparameterization is a clear deterioration of closeness metrics from the calibration to the validation periods. We do not see this within Figure 2 or Table 3, which further justifies our conclusions that we have obtained a successful calibration. The calibrated parameter sets for each watershed can be found in Supplementary Tables 2-4.

\subsection{Streamflow uncertainties from model parameterization}

\subsubsection{Average annual streamflow}


Average annual streamflow from the GCM ensemble for each parameter set and for each watershed is shown in Table 4. The ensemble annual average streamflow were tested for significance differences between the different parameter set simulations, and are shown in Supplementary Table 5. From all three watersheds, there are a total of 30 unique possible combinations of ensemble average streamflow output from the parameter sets. Of these, 20 were found to be significantly different within the Clearwater (6 of 10), Gunnison (7 of 10) and Sacramento (7 of 10) river watersheds (Supplementary Table 5).

Despite the significantly different annual average streamflow for the Clearwater River watershed, there is still clear agreement between parameter sets that the projected average annual streamflow during the 2080s will be lower than historical annual streamflow amounts, with a range of -13.8 to $-4.0 \%$ as compared to the historical annual streamflow (Table 4). For the ensemble average maximum streamflow, two parameter sets project a decrease in annual streamflow and three parameter sets project an increase in annual streamflow, both of which are less than $+/-6 \%$ of historical annual streamflow. Additionally, there is concurrence between parameter sets regarding the ensemble average minimum streamflow. Large decreases in ensemble average minimum streamflow, with a range of -24 to $-17 \%$ decrease compared to the historical average, are projected.

For the Gunnison River watershed, seven possible combinations of ensemble average annual streamflow from the parameter sets were significantly different (Supplementary Table 5). Additionally, annual streamflow output for all parameter sets were significantly different from the historical annual streamflow (Table 4). Three parameter sets lead to an increase in average annual streamflow during the 2080s, with 
the largest having a $37 \%$ increase. One parameter set led to a decrease in ensemble average annual streamflow; however, this decrease was within $6 \%$, resulting in a decline of $4.8 \mathrm{~m}^{3} / \mathrm{s}$, respectively (Table 4 ). For the ensemble average maximum streamflow, there is clear agreement that the Gunnison River watershed will increase in annual streamflow during the 2080 s with a range of 21.1 to $65 \%$. There is also a clear agreement that annual streamflow will decrease or be near historical values for the ensemble average minimum streamflow, with a range from -40.8 to $-3.4 \%$. It is worth noting that the range of streamflow projections were quite large for the ensemble average, maximum, and minimum streamflows.

The ensemble average streamflow was statistically different for seven out of the ten possible unique parameter set combinations for the Sacramento River watershed (Supplementary Table 5). Four of the five parameter sets for the Sacramento River watershed lead to a decrease in ensemble average annual streamflow, ranging from -23.2 to $-8.5 \%$ (Table 4). One parameter set leads to an increase in 2080 s average annual streamflow; however, this increase is minimal (2.2\%) and not significantly different from historical annual streamflow. The rest of the parameter sets lead to significantly different ensemble average annual streamflows compared to historical streamflows. The results for the ensemble average maximum annual streamflow are similar to the ensemble average annual streamflow, with four of the five parameter sets in agreement that a decrease in streamflow is expected. For the ensemble average minimum streamflow, all parameter sets are in agreement of a projected decrease in annual streamflow, with a large range of 33.3 to $-7.7 \%$ change compared to the historical annual streamflow.

\subsubsection{Average monthly streamflow}


Figure 3 presents the GCM ensemble average and uncertainty ranges (maximumminimum range) for monthly streamflows projected from each parameter set for each watershed. The shaded areas represent the GCM projections, the hatched line represents the GCM ensemble average, and the bold line represents the historical average monthly streamflows. All ensemble average monthly streamflow simulations from all parameter sets for all watersheds were found to be significantly different from the historical monthly streamflows. The significance test results for all parameter set combinations are shown in Supplementary Table 6. Of the total 30 unique possible parameter combinations from all three watersheds, the number of statistically different monthly streamflows were higher compared to annual streamflows for the Clearwater ( 8 of 10), Gunnison (9 of 10) and Sacramento (9 of 10) River watersheds.

As seen in Figure 3 for the Clearwater River watershed, the differences in the mean and uncertainty differ between the parameter sets. While all parameter sets agree on a forward shift in streamflow for the Clearwater River watershed, the timing of these shifts differ between parameter sets. For parameter sets 1-3, the streamflow timing shifts 1 month earlier in the year. For parameter sets $4-5$, however, the peak streamflow shifts from May to March, a two-month shift in streamflow. The peak streamflows also differ. The ensemble average monthly peak streamflow for parameter sets 2,3 , and 5 are similar, with peak streamflow values of 180,196 , and $186 \mathrm{~m}^{3} / \mathrm{s}$, respectively. Parameter sets 1 and 4 have higher peak streamflows at 238 and $209 \mathrm{~m}^{3} / \mathrm{s}$, respectively. It is important to note, however, that all parameter sets, as well as their maximum and minimum ranges, have a lower peak streamflow than the historical average largely due to the increase in projected air temperature, resulting in less snowpack accumulation and a 
conversion from snowfall to rainfall. Additionally, the ensemble average minimum streamflows differ. Parameter sets $1,2,4,5$ are in agreement that the minimum streamflow will be in the $10-20 \mathrm{~m}^{3} / \mathrm{s}$ range, while the minimum streamflow for parameter set 3 decreases to $5 \mathrm{~m}^{3} / \mathrm{s}$. Another note is that the largest uncertainty for all parameter sets center around the spring snowmelt period, which will be further discussed, while there is much less uncertainty around the summer season.

In Figure 3, the Gunnison River watershed shows similar findings to the Clearwater River watershed. The significance tests indicate that nine of the ten possible parameter set predictions for monthly streamflows were found to be statistically different amongst each other (Supplementary Table 6). However, as seen in Figure 3, the parameter sets all agree on the ensemble average peak streamflow timing, with a shift from June for the historical time period to May for the 2080s. The peak values differ, however, with a range of $193 \mathrm{~m}^{3} / \mathrm{s}$ for parameter set 5 to $248 \mathrm{~m}^{3} / \mathrm{s}$ for parameter set 2 . It is important to note that for parameter set 5 , the ensemble average and maximum peak streamflow is projected to be much lower than the historical average peak streamflow ( $\sim 65 \mathrm{~m}^{3} / \mathrm{s}$ difference), especially compared to the other parameter set projections. However, when looking at parameter sets 1-4 the average peak streamflow is near or slightly lower than the historical peak streamflow average. For the ensemble average minimum streamflows, the values range from $30 \mathrm{~m}^{3} / \mathrm{s}$ for parameter set 1 to $48 \mathrm{~m}^{3} / \mathrm{s}$ for parameter set 2 . The timing of these ensemble average minimum values differ, however, ranging from July to December depending on the parameter set. Additionally parameter set 4 has a large uncertainty around the fall monsoon season. 
The Sacramento River watershed is not as snowmelt-dependent as the Clearwater and Gunnison River watersheds due to its higher average annual temperature and lower elevations. Therefore, the peak streamflow occurs during the rainy season in the early year and is not as abrupt as the other watersheds. Nine of the potential ten unique ensemble monthly average streamflow outputs were found to be significantly different from each other (Supplementary Table 6). As seen in Figure 3, four of the five parameter sets $(1,2,4,5)$ result in a shift in the peak streamflow from February to January, while the parameter set 3 does not result in a streamflow shift. The ensemble average peak streamflow ranges from around $400 \mathrm{~m}^{3} / \mathrm{s}$ for parameter sets 1 and 2 to $488 \mathrm{~m}^{3} / \mathrm{s}$ to parameter set 3. Additionally, the late winter/early spring season is the source of the largest source of GCM uncertainty. There is a tight uncertainty band around the summer and fall season streamflow, indicating that there will be a certain decrease in fall streamflow. The summer streamflow amounts, however, are different among the parameter sets, with a range of $46 \mathrm{~m}^{3} / \mathrm{s}$ for parameter set 5 to $85 \mathrm{~m}^{3} / \mathrm{s}$ for parameter set 1 .

For the monthly streamflow analysis, nearly all parameter sets agree on a forward shift in streamflow for all watersheds. However, the parameter sets do not agree on the exact timing of this shift except for the Gunnison River watershed, which agree on a June to May monthly peak streamflow shift. Additionally, there is no clear agreement on the magnitude of the peak streamflows from the multiple parameter sets for all watersheds. However, for some watersheds, there is agreement among parameter sets on the direction of these monthly peak streamflows compared to historical values. For the Clearwater and Gunnison River watersheds, all parameter sets generally agree on a decrease in peak 
ensemble average monthly streamflow, while there is no agreement on peak streamflow for the Sacramento River watershed.

\subsection{Snowmelt uncertainties from model parameterization}

All of the watersheds used in this study are snowmelt-dependent and thus an assessment of snowmelt is warranted. Amount and timing of snowmelt for the ensemble average for each parameter set during the 2080s is shown in Figure 4. Observed snowmelt data is not available and therefore no historical snowmelt is displayed in Figure 4. Here we define snowmelt season as the beginning of the rising limb to end of the falling limb of snowmelt, and each parameter set may result in a different snowmelt season length. The peak timing and depth of snowmelt differ for each parameter set for each watershed. For the Clearwater River watershed, peak snowmelt generally occurs in March, with a large range of approximately $2 \mathrm{~mm} / \mathrm{km}^{2}$ (parameter set 2) to $12 \mathrm{~mm} / \mathrm{km}^{2}$ (parameter set 4). The duration of the snowmelt season is also quite different between parameter sets. For parameter sets 1 and 4, not only is more snowmelt generated, but snowmelt is occurring all year (albeit small amounts). This is compared to the other parameter sets, where the snowmelt season only lasts from November to May.

There is also snowmelt uncertainty due to variation among the different parameter sets for the Gunnison River watershed, both in peak snowmelt timing and depth. Three of the parameter sets lead to peak snowmelt in April, while peak snowmelt months for parameter sets 4 and 5 are in May and March, respectively (Figure 4). The peak snowmelt depth also differs for each parameter set, ranging from $0.19 \mathrm{~mm} / \mathrm{km}^{2}$ for parameter set 4 to $0.33 \mathrm{~mm} / \mathrm{km}^{2}$ for parameter set 2 . Due to the size of the Gunnison River watershed (Table 1), minor differences in snowmelt depth can have large 
consequences on total watershed snowmelt. The snowmelt season for the Gunnison River watershed also differs. Four of the five parameter sets lead to a snowmelt season from January to May, while the snowmelt season for parameter set 4 occurs from March to June.

For the Sacramento River watershed, snowmelt is much less and occurs earlier than the Clearwater River and Gunnison River watersheds due to lower elevations and higher average annual temperatures. The snowmelt peaks for the Sacramento River watershed generally occur in February. The snowmelt peak for Parameter set 2, however, peaks in January with another peak in May. The snowmelt peaks for this month range from $0.025 \mathrm{~mm} / \mathrm{km}^{2}$ for parameter set 4 to $0.041 \mathrm{~mm} / \mathrm{km}^{2}$ for parameter set 2 . The season for significant snowmelt for parameter set 2 ranges from November to June, while the snowmelt season for the other parameter sets range from December through April.

\section{Discussion}

Most hydroclimatic studies are based on a model chain where GCM outputs are input into a calibrated hydrologic model with the assumption that realistic hydrologic projections are produced. Previous studies have concentrated on assessing the uncertainty from GCMs, greenhouse gas concentration scenarios or pathways, or hydrologic model parameter sets (Ficklin et al., 2013; Jiang et al., 2007; Maurer, 2007; Poulin et al., 2011; Prudhomme and Davies, 2009b).

Our results agree with the previously-mentioned studies and indicate that the issue of hydrologic model parameter uncertainty and equifinality can lead to significantly different hydrologic results, both at the annual and monthly timescales. Uncertainties in 
monthly streamflow projections due to model parameter uncertainty were larger than annual values (Table 4). A potential reason for this is that the automatic streamflow calibration routine weighted each month equally and therefore each parameter set attempted to achieve a balance between all months. Four model efficiency statistics (NS, $\mathrm{R}^{2}$, RMSE, and PBIAS) were then calculated based on the entire calibration and validation time series and were deemed valid based on the work of Moriasi et al. (2007). In some cases, the parameter set minimized the error between the spring snowmelt months, while for other parameter sets errors in summer streamflow were minimized. For each parameter set, the resulting monthly streamflow is different, where some parameter sets result in lower streamflow/snowmelt peaks at the expense of higher summer streamflow. Nonetheless, uncertainty in streamflow projections were apparent when simulating both annual and monthly values, while the monthly values exhibited higher uncertainties.

This study was performed on watersheds where snowmelt is a component of the hydrologic cycle. What can be seen is that in these snowmelt-dependent mountain watersheds, the hydrologic projections are sensitive to differences in precipitation and temperature projections from GCMs (see, for example, the spread from the GCMs in Figure 3). While most GCMs agree on an air temperature increase, precipitation projections can widely vary (e.g., Ficklin et al., 2013; Harding et al., 2012; Maurer et al., 2007). Additionally, a large amount of uncertainty stems from how the SWAT model uses GCM precipitation and temperature projections to simulate snowpack generation and snowmelt using the previously-discussed snowmelt algorithm. It can be seen from Figures 3 and 4 that the largest uncertainties occur during the spring season when 
precipitation/snowfall and snowmelt is at their highest. This is the opposite as previous work presented by Wilby (2005) for snowless watersheds, where the summer season was the time period with the highest uncertainty. A large parameter uncertainty is likely from the reliance of the SWAT model on temperature index-based approach to estimate snow accumulation and snowmelt processes (Neitsch et al., 2005; Fontaine et al., 2002). Multiple snowfall/snowmelt parameter sets are shown in Supplementary Tables 2-4. In some cases, the parameter sets lead to large snowfall accumulation, and if coupled with a low snowmelt temperature, can lead to large snowmelt pulses earlier in the year. However, if large snowfall accumulation is coupled with a high snowmelt temperature then the snowpack will accumulate and snowmelt will occur later in the season. This occurs in several of the example watersheds where there is no clear agreement on the shift of streamflow timing. If projected streamflow is near the historical average even with large declines in snowmelt, then other hydrologic components such as surface runoff, lateral soil flow, groundwater inflow will have to compensate for this snowmelt decline.

Some drawbacks to our methodology include the assumption that the calibrated parameter sets found during the historical time period remained stationary under future conditions, which may not be a valid assumption (Xu and Singh, 2004; Vaze et al., 2010). Parameter values might change due to different vegetation or climate conditions, and is another source of uncertainty within this study. To address this, one could calibrate a hydrologic model under various sets of conditions (wet vs. dry) during the historical time period (Poulin et al., 2011). This is referred to as 'parameter identifiability' and is further discussed in Wilby (2005). These various parameter sets are likely to result in 
significantly different hydrologic projections, emphasizing a lack of robustness between parameter sets when the climate context is different between the calibration and validation time periods (Vaze et al., 2010; Merz et al., 2011; Coron et al., 2012). For future work, years of high snowpack/snowmelt could be separated from years of low snowpack/snowmelt for SWAT model calibration. A bracketed range of snowpack/snowmelt could then be potentially established.

Additionally, the SWAT model uses the concept of 'global parameters' (single parameters that represent the entire watershed) for many of the parameters used in calibration, such as SURLAG and all of the snowmelt parameters (supplementary Table 1) (Neitsch et al., 2005). For larger watersheds with highly-varied landscapes, such as the watersheds assessed in this study, the use of global parameters may result in a large amount of uncertainty. For example, it may not make physical sense to have the same snowmelt temperature for the entire watershed when there are many different land covers and slopes.

Lastly, it is a difficult exercise to assess which uncertainty dominates (GCM, hydrologic model, parameter set, etc.) the streamflow and snowmelt projections. Note again that Wilby and Harris (2006) ranked uncertainty importance in decreasing order as differences in GCM output, downscaling methods, hydrological model structure, hydrological model parameters, and then greenhouse gas emission scenario. From our analysis, it is clear from Figures 3 and 4 that both parameter uncertainty or equifinality and also the selection of GCM can lead to significantly different results. However, it is evident from Figure 3 that the choice of parameter set dramatically affects the projected streamflow ranges from the GCM ensemble. For example, looking at Figure 3 for 
parameter sets 1 and 5 for the Gunnison River watershed, not only are the GCM ensemble mean streamflow projections significantly different, but the streamflow ranges from the ensemble are quite different. This means that different parameter sets can lead to different GCM ensemble ranges, and therefore the GCM ensemble projection range may also not be robust if only one parameter set is chosen. Therefore, we caution that parameter uncertainty must be accounted for by using a number of parameter sets when looking at hydrologic model projections, especially when using SWAT.

\section{Conclusions}

Using five SWAT model parameter sets that produce adequate calibration and validation metrics in conjunction with downscaled output from five GCMs, this study assesses the uncertainty from multiple parameter sets and GCMs for three western United States watersheds (Clearwater, Gunnison, and Sacramento River watersheds). This work shows that, even though historical calibrations are adequate from all parameter sets, future streamflow projections from downscaled GCMs can vary widely with some projections resulting in lower streamflows and some in higher streamflows compared to historical amounts. The annual streamflow analysis shows that different parameter sets can lead to differences in ensemble average, maximum, and minimum annual streamflows. For the monthly streamflow analysis, nearly all parameter sets agree on a forward shift in streamflow for all watersheds. However, the parameter sets do not agree on the exact timing of this shift except for the Gunnison River watershed. Additionally, there is no clear agreement on the magnitude of the peak streamflows from the multiple parameter sets for all watersheds. 
These large differences in annual and monthly streamflows were calculated using a GCM ensemble, and therefore demonstrate that the uncertainty originates not only from the variations of precipitation and temperature from the GCMs, but also by how the SWAT model uses these GCM precipitation and temperature projections to simulate streamflow, snowpack generation, and snowmelt. The studied watersheds are dependent

on snowmelt, and any differences in snowpack accumulation and snowmelt will result in differences in streamflow.

This work shows that adequate or similar streamflow calibration statistics (hydrological model equifinality) can lead to large differences in streamflow projections under climate change, which has important implications for water resources managers. When developing robust hydroclimatic projections, researchers and water resource managers should account for parameter/hydrologic model uncertainty, and as shown from this work, relying on a single model parameter set for projecting future hydrologic conditions is not robust. Therefore, we suggest that all parameter sets be explored during calibration and validation, and projections from all valid parameter sets should be used to increase the robustness of the results and confidence in the directions and trends of the projections.

\section{Acknowledgements}

We acknowledge the World Climate Research Programme's Working Group on Coupled Modelling, which is responsible for CMIP, and thank the climate modeling groups (listed in Table 2 of this paper) for producing and making available their model output. For CMIP the U.S. Department of Energy's Program for Climate Model Diagnosis and Intercomparison provides coordinating support and led development of 
software infrastructure in partnership with the Global Organization for Earth System

Science Portals.

\section{References}

Abbaspour, K.C. et al., 2007. Modelling hydrology and water quality in the prealpine/alpine Thur watershed using SWAT. Journal of Hydrology, 333(2-4): 413430.

Anderson, E.A., 1976. A Point Energy and Mass Balance Model of a Snow Cover. NOAA Techincal Report NWS 19: 150 pp.

Arnell, N., Lloyd-Hughes, B., 2014. The global-scale impacts of climate change on water resources and flooding under new climate and socio-economic scenarios. Climatic Change, 122(1-2): 127-140.

Arnold, J.G., Srinivasan, R., Muttiah, R.S., Williams, J.R., 1998. Large Area Hydrologic Modeling and Assessment Part I: Model Development. Journal of the American Water Resources Association, 34(1): 73-89.

Barnett, T.P. et al., 2008. Human-Induced Changes in the Hydrology of the Western United States. Science, 319(5866): 1080-1083, doi:10.1126/science.1152538.

Beven, K., 2006. A manifesto for the equifinality thesis. Journal of Hydrology, 320(1-2): 18-36.

Brigode, P., Oudin, L., Perrin, C., 2013. Hydrological model parameter instability: A source of additional uncertainty in estimating the hydrological impacts of climate change? Journal of Hydrology, 476(0): 410-425.

Chen, J., Brissette, F.P., Leconte, R., 2011a. Uncertainty of downscaling method in quantifying the impact of climate change on hydrology. Journal of Hydrology, 401(3-4): 190-202.

Chen, J., Brissette, F.P., Poulin, A., Leconte, R., 2011b. Overall uncertainty study of the hydrological impacts of climate change for a Canadian watershed. Water Resources Research, 47(12): W12509.

Coron, L., Andreassian, V., Perrin, C., Lerat, J., Vaze, J., Bourqui, M., Hendrickz, F., 2012. Crash testing hydrological models in contrasted climate conditions: An experiment on 216 Austrailian catchments. Water Resources Research, 48: W05552.

Diffenbaugh, N.S., Pal, J.S., Trapp, R.J., Giorgi, F., 2005. Fine-scale processes regulate the response of extreme events to global climate change. Proceedings of the National Academy of Sciences of the United States of America, 102(44): 1577415778.

Efstratiadis, A., Koutsoyiannis, D., 2010. One decade of multi-objective calibration approaches in hydrological modelling: a review. Hydrological Sciences Journal, 55(1): 58-78.

Ficklin, D.L., Stewart, I.T., Maurer, E.P., 2013. Climate Change Impacts on Streamflow and Subbasin-Scale Hydrology in the Upper Colorado River Basin. PLoS ONE, 8(8): e71297. 
Fontaine, T.A., Cruickshank, T.S., Arnold, J.G., Hotchkiss, R.H., 2002. Development of a snowfall-snowmelt routine for mountainous terrain for the soil water assessment tool (SWAT). Journal of Hydrology, 262(1-4): 209-223.

Gesch, D. et al., 2002. The National Elevation Dataset. Photogrammetric Engineering and Remote Sensing, 68(1).

Gutmann, E.D, Rasmussen, R.M., Liu, C., Ikeda, K., Gochis, D.J., Clark, M.P., Dudhia, J., Thompson, G., 2012. A Comparison of Statistical and Dynamical Downscaling of Winter Precipitation over Complex Terrain. Journal of Climate, 25: 262-281.

Harding, B.L., Wood, A.W., Prairie, J.R., 2012. The implications of climate change scenario selection for future streamflow projection in the Upper Colorado River Basin. Hydrol. Earth Syst. Sci. Discuss., 16: 3989-4007.

Homer, C., Huang, C., Yang, L., Wylie, B., Coan, M., 2004. Development of a 2001 National Land-Cover Database for the United States. Photogrammetric Engineering and Remote Sensing, 70: 829-840.

Jiang, T. et al., 2007. Comparison of hydrological impacts of climate change simulated by six hydrological models in the Dongjiang Basin, South China. Journal of Hydrology, 336(3-4): 316-333.

Kay, A.L., Davies, H.N., Bell, V.A., Jones, R.G., 2009. Comparison of uncertainty sources for climate change impacts: flood frequency in England. Climatic Change, 92: 41-63, doi:10.1007/s10584-008-9471-4.

Kim, J., Choi, J., Choi, C., Park, S., 2013. Impacts of changes in climate and land use/land cover under IPCC RCP scenarios on streamflow in the Hoeya River Basin, Korea. Science of The Total Environment, 452-453(0): 181-195.

Kollat, J.B., Reed, P.M., Wagener, T., 2012. When are multiobjective calibration tradeoffs in hydrologic models meaningful? Water Resources Research, 48(3): W03520.

Leung, L.R. et al., 2004. Mid-century ensemble regional climate change scenarios for the western United States. Climatic Change, 62(1-3): 75-113.

Maurer, E.P., 2007. Uncertainty in hydrologic impacts of climate change in the Sierra Nevada, California under two emissions scenarios. Climatic Change, 82(3-4 ): 309-325, doi:10.1007/s10584-006-9180-9.

Maurer, E.P., Brekke, L., Pruitt, T., Duffy, P.B., 2007. Fine-resolution climate change projections enhance regional climate change impact studies. Eos, Transactions, American Geophysical Union, 88(47): 504, doi:10.1029/2007EO470006.

Maurer, E.P., Hidalgo, H.G., Das, T., Dettinger, M.D., Cayan, D.R., 2010. The utility of daily large-scale climate data in the assessment of climate change impacts on daily streamflow in California. Hydrol. Earth Syst. Sci., 14(6): 1125-1138.

Maurer, E.P., Wood, A.W., Adam, J.C., Lettenmaier, D.P., Nijssen, B., 2002. A longterm hydrologically-based data set of land surface fluxes and states for the conterminous United States. Journal of Climate, 15(22): 3237-3251.

McKay, M.D., Beckman, R.J., Conover, W.J., 1979. Comparison of Three Methods for Selecting Values of Input Variables in the Analysis of Output from a Computer Code. Technometrics, 21(2): 239-245.

Merz, R., Parajka, J., Blöschl, G., 2011. Time stability of catchment model parameters: implications for climate change impact analyses. Water Resources Research, 47, W02531. 
Minville, M., Brissette, F., Leconte, R., 2008. Uncertainty of the impact of climate change on the hydrology of a nordic watershed. Journal of Hydrology, 358(1-2): 70-83.

Moriasi, D.N. et al., 2007. Model Evaluation Guidelines for Systematic Quantification of Accuracy in Watershed Simulations. Trans. of the ASABE, 50(3): 885-900.

Murphy, J.M. et al., 2004. Quantification of modelling uncertainties in a large ensemble of climate change simulations. Nature, 430(7001): 768-772.

Nash, J.E., Sutcliffe, J.V., 1970. River flow forecasting through conceptual models part I -- A discussion of principles. Journal of Hydrology, 10(3): 282-290.

Neitsch, S.L., Arnold, J.G., Kiniry, J.R., Williams, J.R., King, K.W., 2005. Soil and Water Assessment Tool Theoretical Documentation: Version 2005. Texas Water Resources Institute, College Station, TX.

Poulin, A., Brissette, F., Leconte, R., Arsenault, R., Malo, J.-S., 2011. Uncertainty of hydrological modelling in climate change impact studies in a Canadian, snowdominated river basin. Journal of Hydrology, 409(3-4): 626-636.

Prudhomme, C., Davies, H., 2009a. Assessing uncertainties in climate change impact analyses on the river flow regimes in the UK. Part 1: baseline climate. Climatic Change, 93(1-2): 177-195.

Prudhomme, C., Davies, H., 2009b. Assessing uncertainties in climate change impact analyses on the river flow regimes in the UK. Part 2: future climate. Climatic Change, 93(1-2): 197-222.

Santhi, C. et al., 2001. Validation of the SWAT model on a large river basin with poin and nonpoin sources. Journal of the American Water Resources Association, 37(5): 1169-1188.

Steffens, K. et al., 2014. Modelling pesticide leaching under climate change: parameter vs. climate input uncertainty. Hydrol. Earth Syst. Sci., 18(2): 479-491.

Trujillo, E., Molotch, N.P., 2014. Snowpack regimes of the Western United States. Water Resources Research, doi: 10.1002/2013WR014753

USBR, 2011. West-Wide Climate Risk Assessments: Bias-Corrected and Spatially Downscaled Surface Water Projections. U.S. Bureau of Reclatmation, Denver, Colorado.

Vaze, J., Post, D.A., Chiew, F.H.S., Perraud, J.-M, Viney, N.R., Teng, J., 2010. Climate non-stationarity - Validty of calibrated rainfall-runoff models for use in climate change studies. Journal of Hydrology, 394: 447-457.

Wilby, R.L., Harris, I., 2006. A framework for assessing uncertainties in climate change impacts: low-flow scenarios for the River Thames, UK. Water Resources Research, 42: W02419, doi:10.1029/2005WR004065.

Wolock, D.M., 1997. STATSGO soil characteristics for the conterminous United States. In: Survey, U.S.G. (Ed.). Open-File Report, Washington D.C., United States.

Wood, A.W., Leung, L.R., Sridhar, V., Lettenmaier, D.P., 2004. Hydrologic implications of dynamical and statistical approaches to downscaling climate model outputs. Climatic Change, 62(1-3): 189-216.

Xu, C.-Y, Sing, V.P., 2004. Review on regional water resources assessment models under stationarity and changing climate. Water Resource Management, 18: 591-612, 


\section{Table and Figure Captions}

Table 1. Watershed characteristics for the Clearwater River watershed near Beaver Creek, Gunnison River watershed at Whitewater, Colorado, and Sacramento River watershed at Lake Shasta

Table 2. Downscaled General Circulation Models used in this study

Table 3. Streamflow calibration and validation statistics for the Clearwater, Gunnison, and Sacramento River watersheds for each parameter set. NS: Nash-Sutcliffe coefficient; R2: coefficient of determination; RMSE: root mean square error $\left(\mathrm{m}^{3} / \mathrm{s}\right)$; pbias: Percent Bias

Table 4. Average annual streamflow percent difference of the 2080s from the historical time period. The average annual streamflows for the Clearwater River, Gunnison River, and Sacramento River watersheds are 96,87 , and $239 \mathrm{~m}^{3} / \mathrm{s}$.

Figure 1. The western United States watersheds assessed in this study.

Figure 2. Kernal density plots for the calibration and validation time periods for all watersheds. The vertical line at 0 represents no difference between the observed and simulated streamflows.

Figure 3. Ensemble average monthly (hatched line) and the maximum and minimum ensemble streamflow range (grey area) during the 2080s for each watershed in this study. The black line represents the historical observed monthly streamflow.

Figure 4. Ensemble average snowmelt depth $(\mathrm{mm})$ per unit watershed area $\left(\mathrm{km}^{2}\right)$ during the 2080s for each parameter set and each watershed 


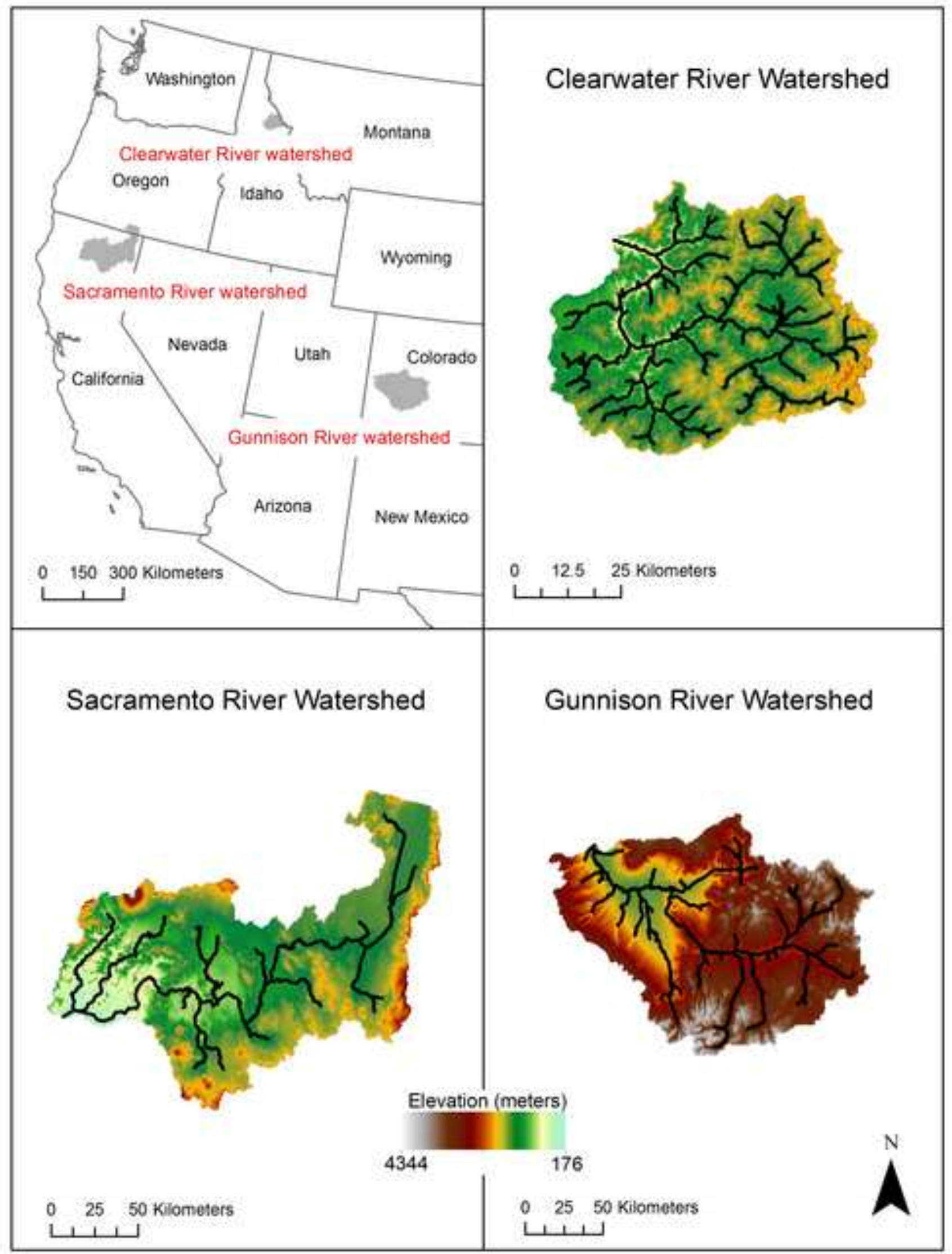


Figure 2

\section{Calibration Period}
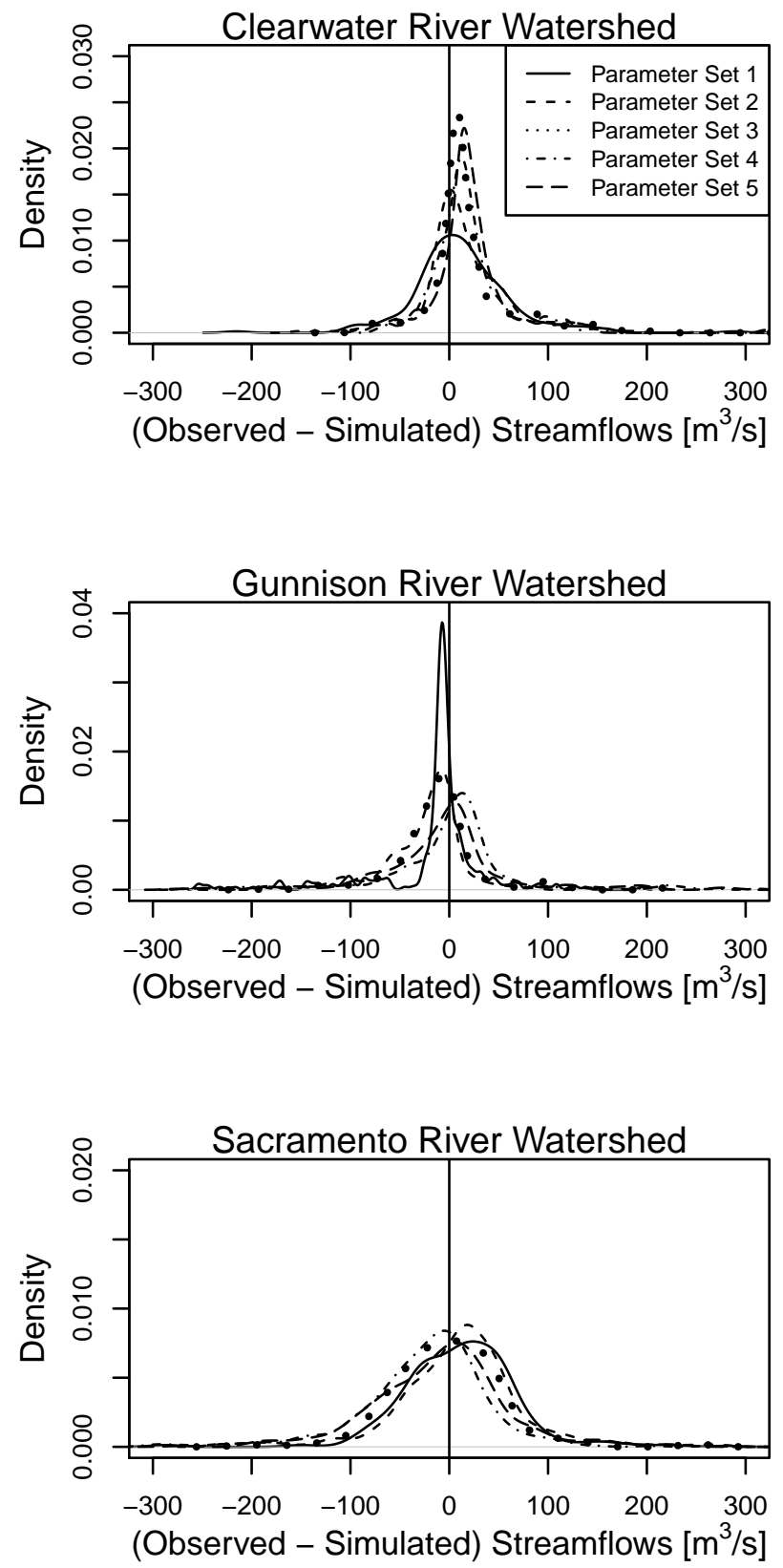

Validation Period
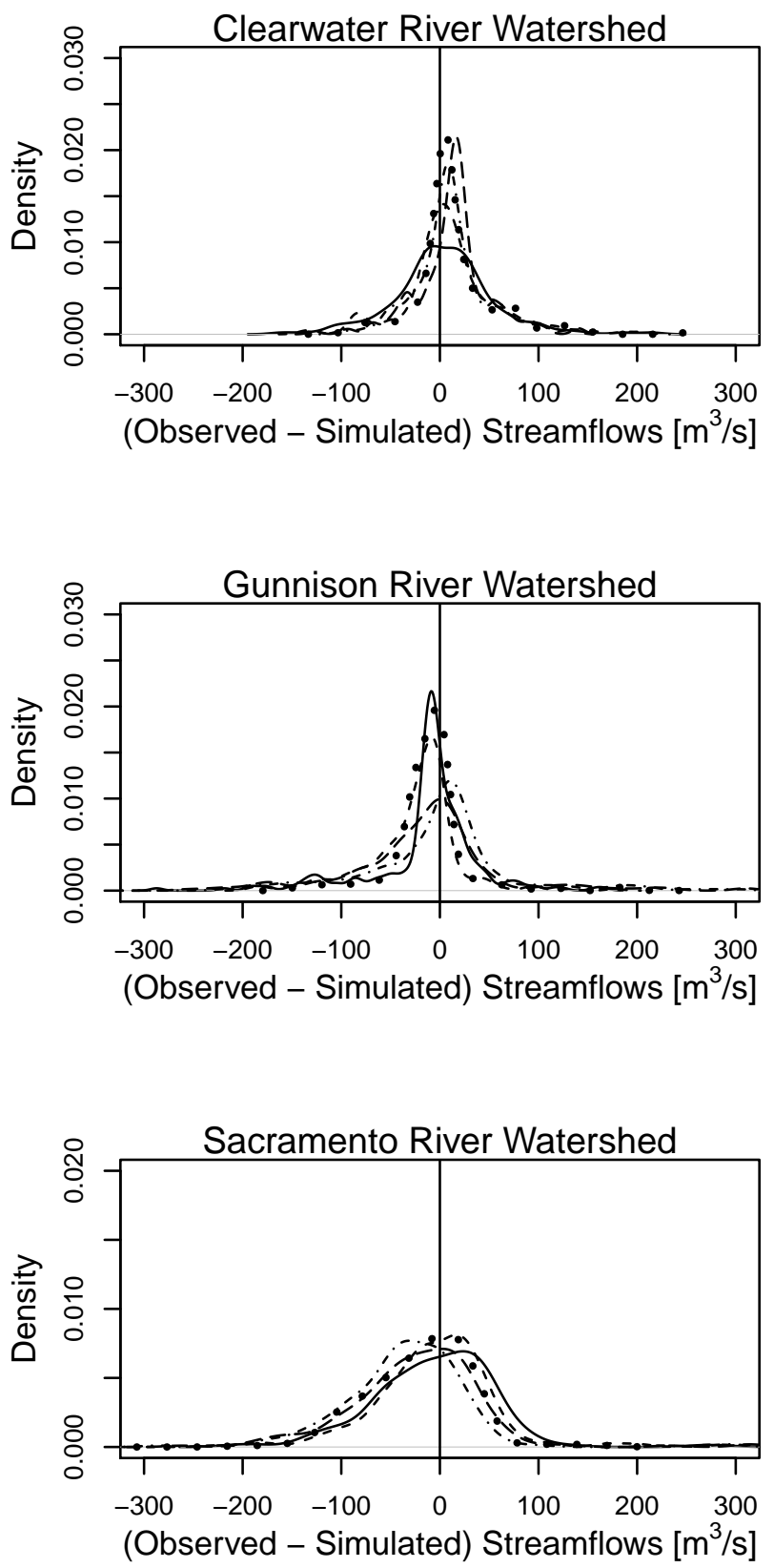

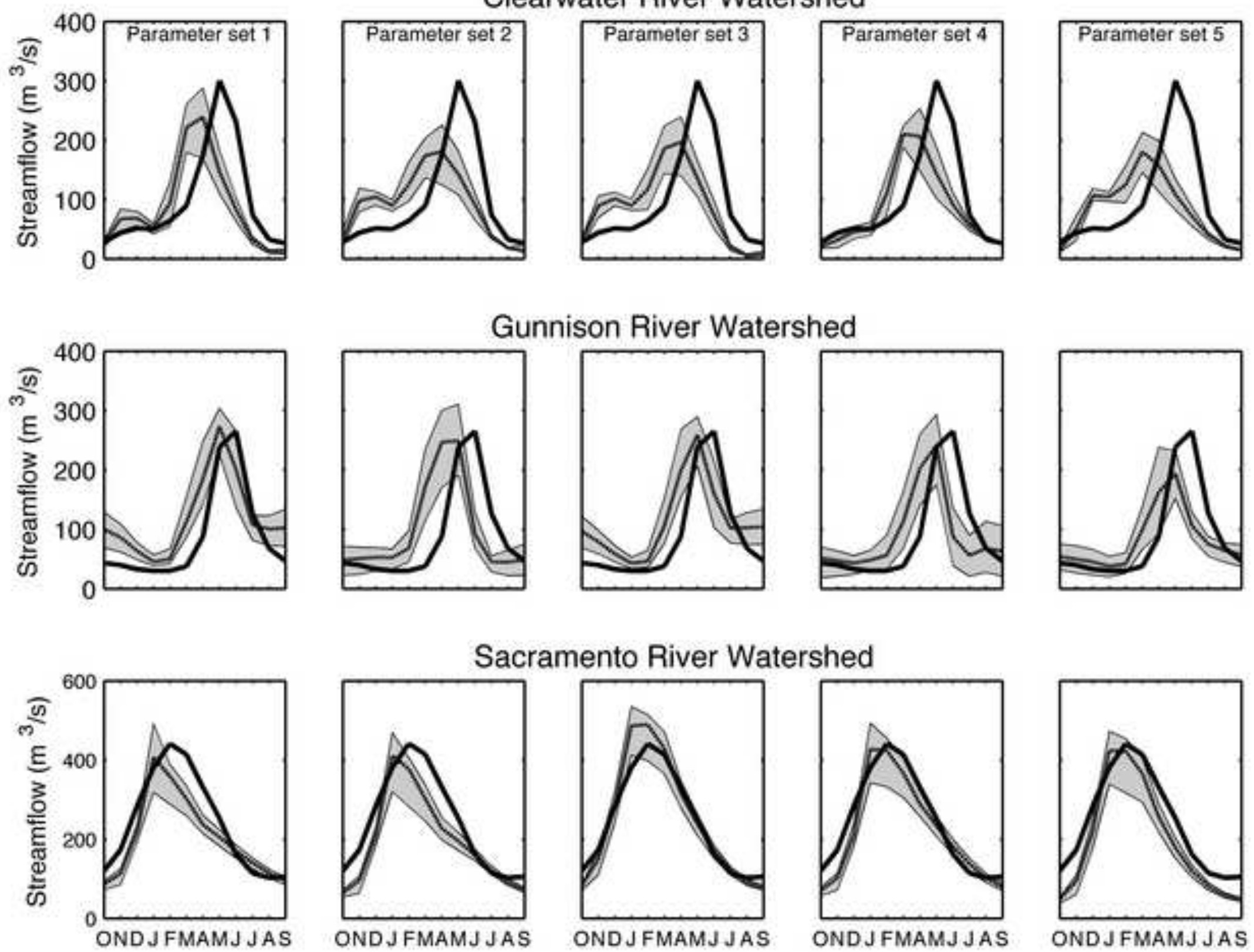


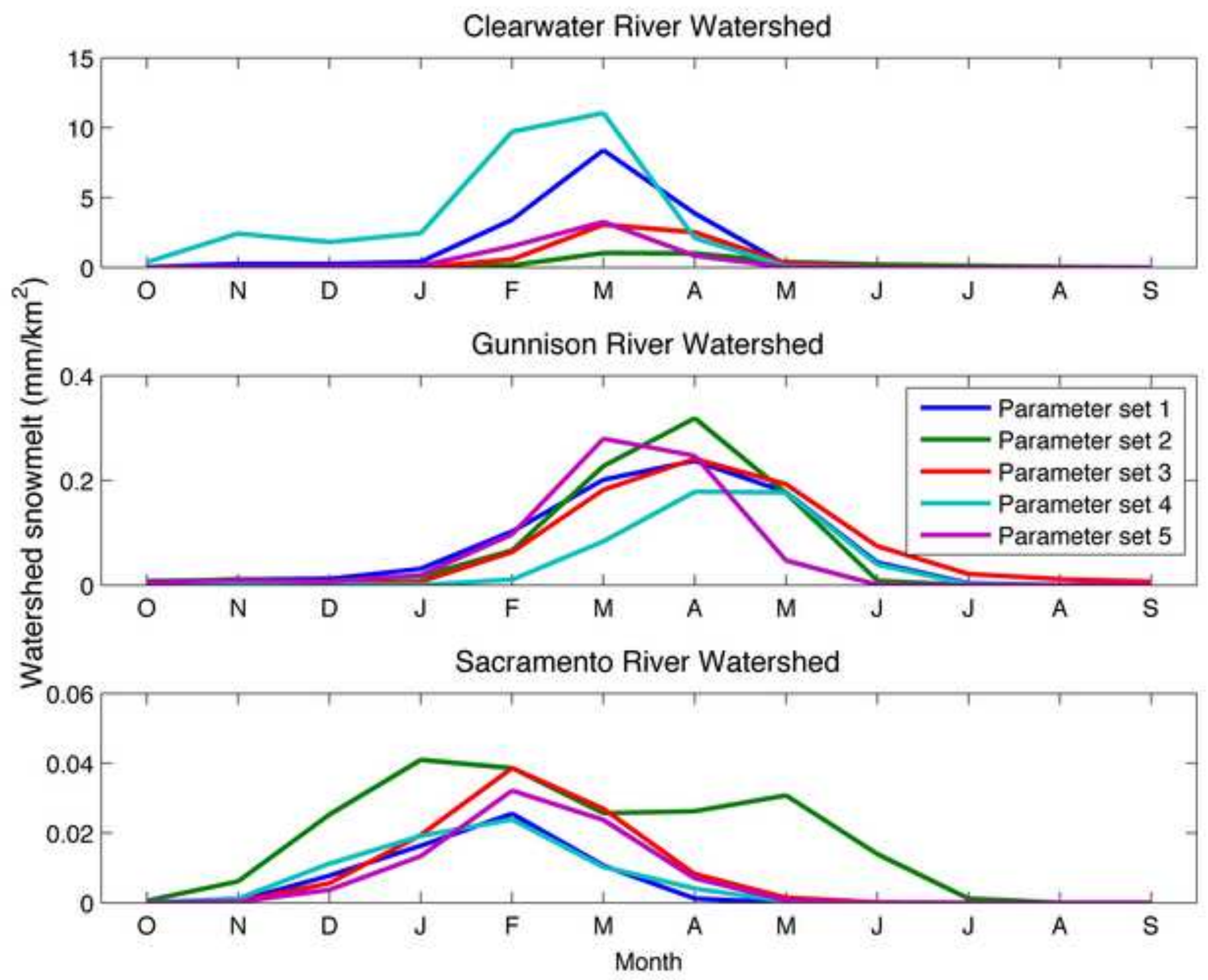


Table 1. Watershed characteristics for the Clearwater River watershed near Beaver Creek, Gunnison River watershed at Whitewater, Colorado, and Sacramento River watershed at Lake Shasta

\begin{tabular}{|c|c|c|c|}
\hline Watershed & Clearwater River & Gunnison River & Sacramento River \\
\hline \multirow{2}{*}{ Watershed Outlet Coordinates } & $\begin{array}{c}46^{\circ} 50^{\prime} 34.334^{\prime \prime} \mathrm{N} \\
115^{\circ} 37^{\prime} 16.97^{\prime \prime} \mathrm{W}\end{array}$ & $\begin{array}{c}38^{\circ} 59^{\prime} 0.193^{\prime \prime} \mathrm{N} \\
108^{\circ} 27^{\prime} 7.165^{\prime \prime} \mathrm{W}\end{array}$ & $\begin{array}{c}40^{\circ} 42^{\prime} 45.557^{\prime \prime} \mathrm{N} \\
122^{\circ} 25^{\prime} 59.872^{\prime \prime} \mathrm{W}\end{array}$ \\
\hline Area $\left(\mathrm{km}^{2}\right)$ & 3,354 & 20,048 & 18,839 \\
\hline Max. elevation $(\mathrm{m})$ & 2415 & 4344 & 4298 \\
\hline Min. elevation $(\mathrm{m})$ & 509 & 1267 & 176 \\
\hline Ave. streamflow $\left(\mathrm{m}^{3} / \mathrm{s}\right)$ & 96.8 & 87.1 & 239.9 \\
\hline Ave. Annual Temp $\left({ }^{\circ} \mathrm{C}\right)$ & 5.6 & 1.3 & 9.4 \\
\hline Average annual precip. $(\mathrm{mm})$ & 1410 & 520 & 890 \\
\hline
\end{tabular}


Table 2. Downscaled General Circulation Models used in this study

\begin{tabular}{ll}
\hline Modeling Group & CMIP5 Model \\
\hline Canadian Centre for Climate Modeling \& Analysis & canesm2 \\
\hline $\begin{array}{l}\text { Météo-France / Centre National de Recherches } \\
\text { Météorologiques, France }\end{array}$ & cnrm-cm5 \\
$\begin{array}{ll}\text { Geophysical Fluid Dynamics Laboratory, USA } \\
\text { Institut Pierre Simon Laplace, France }\end{array}$ & gfdl-cm3 \\
$\begin{array}{l}\text { Center for Climate System Research (The University of } \\
\text { Tokyo), National Institute for Environmental Studies, and } \\
\text { Frontier Research Center for Global Change (JAMSTEC), }\end{array}$ & miroc5 \\
Japan & \\
\hline
\end{tabular}


Table 3. Streamflow calibration and validation statistics for the Clearwater, Gunnison, and Sacramento River watersheds for each parameter set. NS: Nash-Sutcliffe coefficient; $\mathrm{R}^{2}$ : coefficient of determination; RMSE: root mean square error $\left(\mathrm{m}^{3} / \mathrm{s}\right)$; $\mathrm{pbias:} \mathrm{Percent}$ Bias

\begin{tabular}{|c|c|c|c|c|c|c|c|c|c|c|c|}
\hline & & \multicolumn{5}{|c|}{ Calibration } & \multicolumn{5}{|c|}{ Validation } \\
\hline & & Years & NS & $\mathrm{R}^{2}$ & RMSE & pbias (\%) & Years & NS & $\mathrm{R}^{2}$ & RMSE & $\operatorname{pbias}(\%)$ \\
\hline \multirow{5}{*}{ 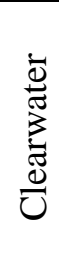 } & Parameter Set 1 & 1970-1989 & 0.70 & 0.80 & 57.8 & 19.9 & 1990-2005 & 0.66 & 0.79 & 55.5 & 15.0 \\
\hline & Parameter Set 2 & 1970-1989 & 0.79 & 0.84 & 48.5 & 20.4 & 1990-2005 & 0.83 & 0.85 & 34.3 & 10.4 \\
\hline & Parameter Set 3 & 1970-1989 & 0.81 & 0.86 & 45.5 & 21.2 & 1990-2005 & 0.82 & 0.87 & 35.8 & 13.7 \\
\hline & Parameter Set 4 & 1970-1989 & 0.76 & 0.79 & 52.1 & 18.7 & $1990-2005$ & 0.71 & 0.74 & 50.7 & 11.2 \\
\hline & Parameter Set 5 & 1970-1989 & 0.72 & 0.76 & 56.7 & 21.3 & 1990-2005 & 0.77 & 0.79 & 45.8 & 13.8 \\
\hline \multirow{5}{*}{ 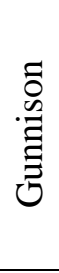 } & Parameter Set 1 & 1960-1984 & 0.73 & 0.74 & 51.8 & 2.6 & 1985-2005 & 0.76 & 0.76 & 45.8 & 5.7 \\
\hline & Parameter Set 2 & 1960-1984 & 0.64 & 0.73 & 60.5 & -17.8 & $1985-2005$ & 0.62 & 0.7 & 57.1 & -14.7 \\
\hline & Parameter Set 3 & 1960-1984 & 0.72 & 0.73 & 53.2 & -12.0 & $1985-2005$ & 0.75 & 0.76 & 46.0 & -8.8 \\
\hline & Parameter Set 4 & 1960-1984 & 0.70 & 0.78 & 55.0 & -15.9 & $1985-2005$ & 0.68 & 0.77 & 52.7 & -15.0 \\
\hline & Parameter Set 5 & 1960-1984 & 0.78 & 0.8 & 47.4 & -14.9 & $1985-2005$ & 0.77 & 0.79 & 44.2 & -12.3 \\
\hline \multirow{5}{*}{ 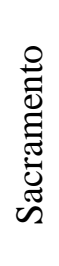 } & Parameter Set 1 & 1950-1984 & 0.85 & 0.87 & 74.7 & -8.7 & $1985-2005$ & 0.84 & 0.89 & 77.3 & -16.1 \\
\hline & Parameter Set 2 & 1950-1984 & 0.84 & 0.84 & 77.3 & -3.1 & $1985-2005$ & 0.85 & 0.87 & 75.2 & -11.0 \\
\hline & Parameter Set 3 & 1950-1984 & 0.91 & 0.93 & 60.3 & -6.2 & $1985-2005$ & 0.86 & 0.93 & 72.3 & -19.6 \\
\hline & Parameter Set 4 & 1950-1984 & 0.86 & 0.86 & 73.5 & 18.1 & $1985-2005$ & 0.87 & 0.87 & 71.9 & 19.1 \\
\hline & Parameter Set 5 & 1950-1984 & 0.93 & 0.92 & 54.8 & -6.9 & $1985-2005$ & 0.90 & 0.93 & 60.5 & -7.14 \\
\hline
\end{tabular}


1 Table 4. Average annual streamflow percent difference of the 2080s from the historical time period. The

2 average annual streamflows for the Clearwater River, Gunnison River, and Sacramento River watersheds

3 are 96,87 , and $239 \mathrm{~m}^{3} / \mathrm{s}$.

\begin{tabular}{|c|c|c|c|c|}
\hline & Parameter Set & $\begin{array}{c}\text { Ensemble } \\
\text { Average Annual } \\
\text { Streamflow (\%) }\end{array}$ & $\begin{array}{c}\text { Ensemble Maximum } \\
\text { Ave. Annual Streamflow } \\
(\%)\end{array}$ & $\begin{array}{c}\text { Ensemble Minimum } \\
\text { Ave. Annual } \\
\text { Streamflow (\%) }\end{array}$ \\
\hline \multirow{5}{*}{ 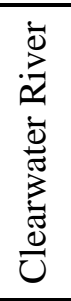 } & 1 & -8.8 & 1.0 & -21.5 \\
\hline & 2 & -4.0 & 5.2 & -17.1 \\
\hline & 3 & -8.9 & 1.1 & -21.9 \\
\hline & 4 & -11.0 & -1.9 & -21.8 \\
\hline & 5 & -13.8 & -4.6 & -24.2 \\
\hline \multirow{5}{*}{ 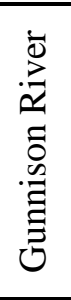 } & 1 & 36.7 & 65.3 & 3.4 \\
\hline & 2 & 12.1 & 39.0 & -26.2 \\
\hline & 3 & 29.8 & 59 & -3.4 \\
\hline & 4 & 3.2 & 36.9 & -40.8 \\
\hline & 5 & -5.5 & 21.1 & -37.0 \\
\hline \multirow{5}{*}{ 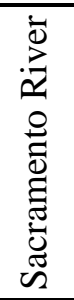 } & 1 & -14.7 & -6.9 & -24.7 \\
\hline & 2 & -19.0 & -12.2 & -29.7 \\
\hline & 3 & -23.2 & -16.4 & -33.3 \\
\hline & 4 & $2.2 *$ & 9.5 & -7.7 \\
\hline & 5 & -8.5 & -0.7 & -20.0 \\
\hline
\end{tabular}

$4 *$ represents no significant difference from the historical streamflows at $\mathrm{p}=0.05$ 